\title{
Realization of SVM Algorithm for Indirect Matrix Converter and Its Application in Power Factor Control
}

\author{
Gang Li \\ College of Instrumentation and Electrical Engineering, Jilin University, Changchun 130061, China \\ Correspondence should be addressed to Gang Li; ligang2013@jlu.edu.cn
}

Received 18 June 2015; Revised 14 August 2015; Accepted 26 August 2015

Academic Editor: Don Mahinda Vilathgamuwa

Copyright (C) 2015 Gang Li. This is an open access article distributed under the Creative Commons Attribution License, which permits unrestricted use, distribution, and reproduction in any medium, provided the original work is properly cited.

\begin{abstract}
Compared with AC-DC-AC converter, matrix converter (MC) has several advantages for its bidirectional power flow, controllable power factor, and the absence of large energy storage in dc-link. The topology of MC includes direct matrix converter (DMC) and indirect matrix converter (IMC). IMC has received great attention worldwide because of its easy implementation and safe commutation. Space vector PWM (SVM) algorithm for indirect matrix converter is realized on DSP and CPLD platform in this paper. The control of the rectifier and inverter in IMC can be decoupled because of the intermediate dc-link. The space vector modulation scheme for IMC is discussed and the PWM sequences for the rectifier and inverter are generated. And a two-step commutation of zero current switching (ZCS) in the rectifier is achieved. Input power factor of IMC can be changed by adjusting the angle of the reference current vector. Experimental tests have been conducted on a RB-IGBT based indirect matrix converter prototype. The results verify the performance of the SVM algorithm and the ability of power factor correction.
\end{abstract}

\section{Introduction}

$\mathrm{AC} / \mathrm{AC}$ conversion has two main types: AC-DC-AC converters and direct $\mathrm{AC} / \mathrm{AC}$ converters. AC-DC-AC converters include the current and voltage source topologies with a capacitor or inductor in the dc-link. Direct AC/AC converters include the cycloconverter of high-power applications and matrix converters in low power range [1]. Matrix converter has a compact structure without capacitor or inductor, which has received much attention in the academic and industrial fields worldwide in recent years [2-6]. Since Alesina and Venturini proposed a control method for matrix converter using a mathematical approach to generate the desired output voltage [7], the PWM algorithms for matrix converters become a research focus. New PWM strategies for matrix converters have been proposed in recent years [8-13]. Some researcher concentrated on the realization of the PWM schemes, such as dipolar modulation technique [8], SHEPWM [9], and beatless synchronous PWM [10]. The PWM strategies for matrix converter are also proposed to reduce the ripple in the input and output waveforms [11,12]. In the high-power applications, indirect SVPWM for multimodular matrix converters is realized [13].
The topologies of matrix converter, including direct matrix converter and indirect matrix converter [14-16], are another research focus in $\mathrm{AC} / \mathrm{AC}$ conversion. Compared with the former one, IMC has several advantages. (1) With a real dc-link, the converter consists of two stages, a rectifier and an inverter. The control of the two stages can be decoupled and the control difficulty is lowered down. (2) With appropriate modulation method, zero-current switching commutation in the rectifier can be simply accomplished. The system efficiency is improved. (3) The number of power switches can be further reduced. (4) With the dc-link, multioutput IMC can be realized $[17,18]$. The topology of IMC is shown in Figure 1. The bidirectional switch in the rectifier stage is composed by two RB-IGBTs.

The PWM strategies in [7-13] are proposed for DMC. In [19-22], the conventional PWM algorithm, based on two larger source line voltages, is proposed. The PWM period of the rectifier stage is divided in two segments to reduce the switching times and the harmonics of the input current. But these PWM strategies have no zero vectors. In [23-26], carrier-PWM realization and overmodulation method for IMC are discussed. 


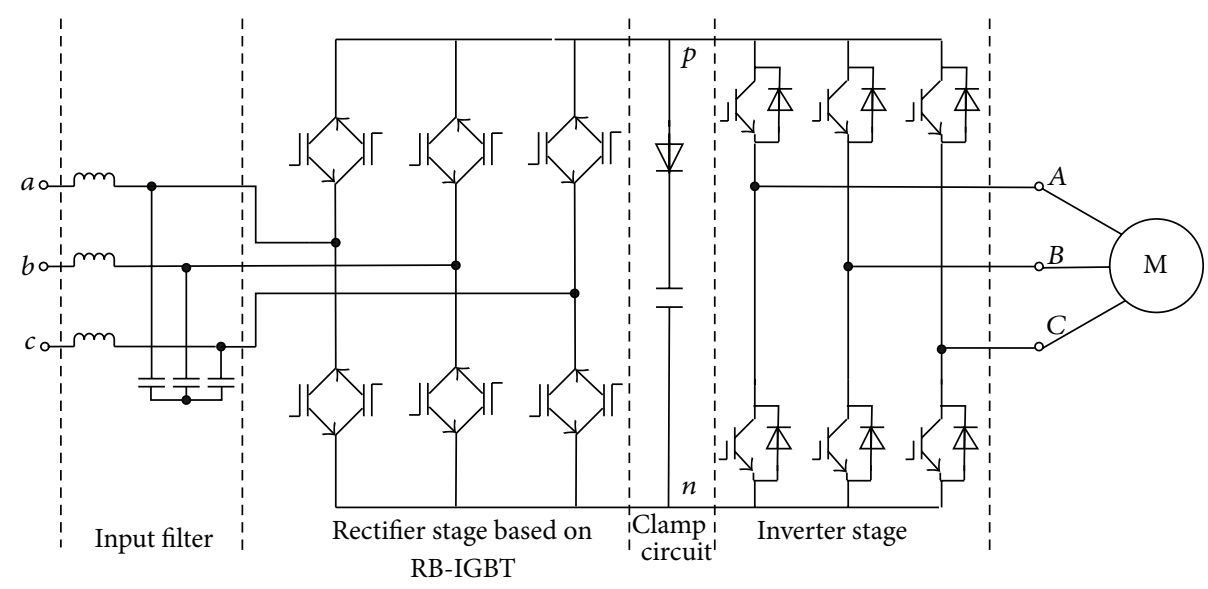

FIGURE 1: Topology of indirect matrix converter using RB-IGBT.

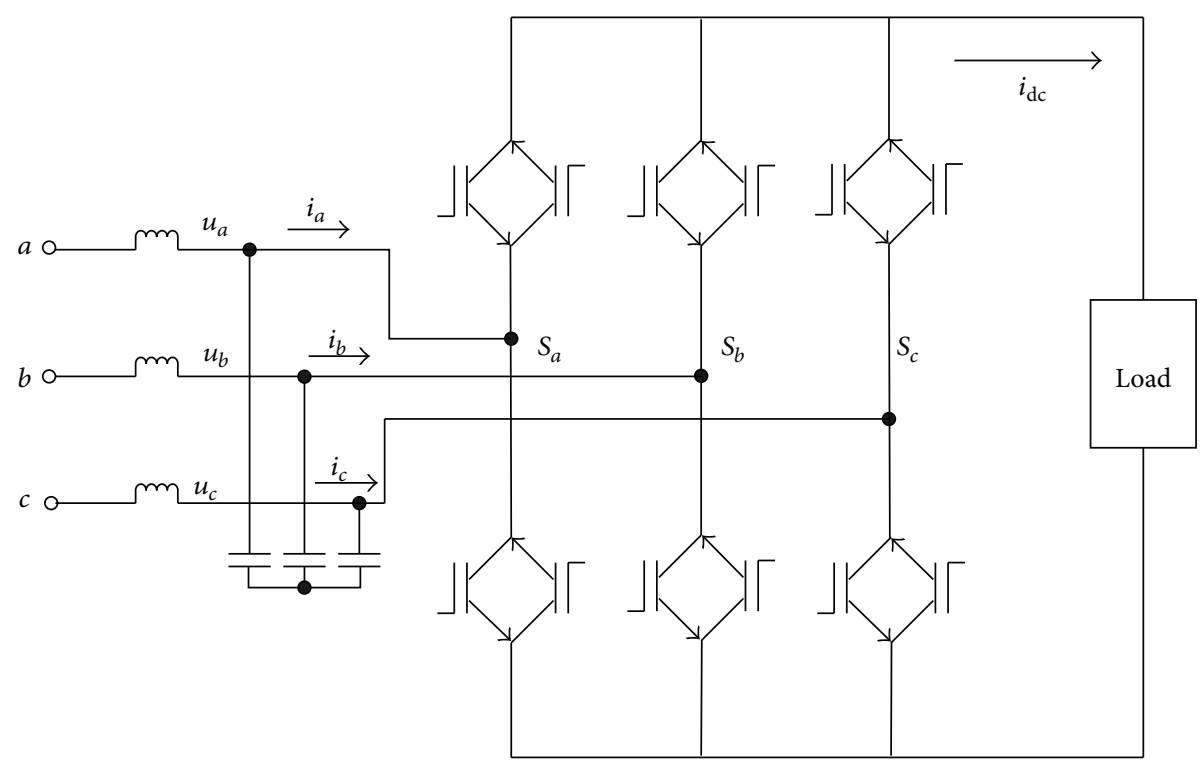

FIGURE 2: Control principle of the rectifier.

In the applications of indirect matrix converter, [27] proposes IMC to control doubly fed induction generation for wind power system. IMC is used to control a microturbine generator [28]. A multimodular indirect matrix converter topology is proposed to be a frequency converter used in the medium-voltage motion drive systems [29]. And three level neutral-point-clamped indirect matrix converters are proposed in [30].

In this paper, the rectifier is controlled as a currentsource converter and inverter is controlled as a voltage-source converter. SVM is applied for the rectifier and SVPWM is applied for the inverter. The PWM sequence for indirect matrix converter is achieved. Two-step commutation of zerocurrent switching for the rectifier is presented. The principle of the input power factor correction for IMC is discussed. The design and implementation of indirect matrix converter prototype using RB-IGBT are introduced. The experimental results are shown to verify the performance of the proposed PWM algorithm and the ability of PFC.

\section{Space Vector Modulation of IMC}

2.1. PWM Algorithm of IMC. The control of the rectifier and inverter for IMC can be decoupled because of the dc-link. The rectifier is controlled as a current-source converter, and the inverter can be seen as an inductive load in dc-link, shown in Figure 2.

Three phase input currents can be defined as follows:

$$
i_{j}=S_{j} \cdot i_{\mathrm{dc}} \quad j=a, b, c .
$$

In (1), $S_{j}$ is the switch function. $S_{j}$ can be 1,0 , and -1 , which are shown in Figure 3. The switching functions of the rectifier are shown in Table 1.

Current space vector can be defined as follows:

$$
I=i_{a}+i_{b} \cdot \mathrm{e}^{j 2 \pi / 3}+i_{c} \cdot \mathrm{e}^{-j 2 \pi / 3} .
$$

From (1) and (2),

$$
I=i_{\mathrm{dc}}\left(S_{a}+S_{b} \cdot \mathrm{e}^{j 2 \pi / 3}+S_{c} \cdot \mathrm{e}^{-j 2 \pi / 3}\right) .
$$




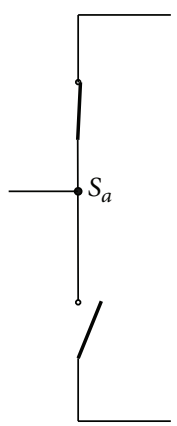

(a) $S_{a}=1$

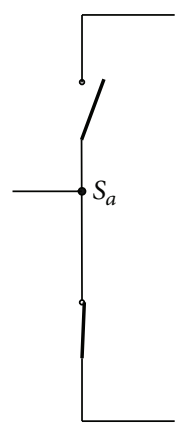

(b) $S_{a}=-1$

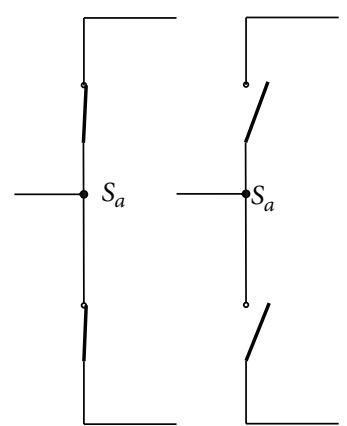

(c) $S_{a}=0$

FIgURE 3: The statues of $S_{a}$.

TABLE 1: Switching functions of the rectifier.

\begin{tabular}{lccc}
\hline Number & $S_{a}$ & $S_{b}$ & $S_{c}$ \\
\hline 1 & 1 & 0 & -1 \\
2 & 0 & 1 & -1 \\
3 & -1 & 1 & 0 \\
4 & -1 & 0 & 1 \\
5 & 0 & -1 & 1 \\
6 & 1 & -1 & 0 \\
7 & 0 & 0 & 0 \\
\hline
\end{tabular}

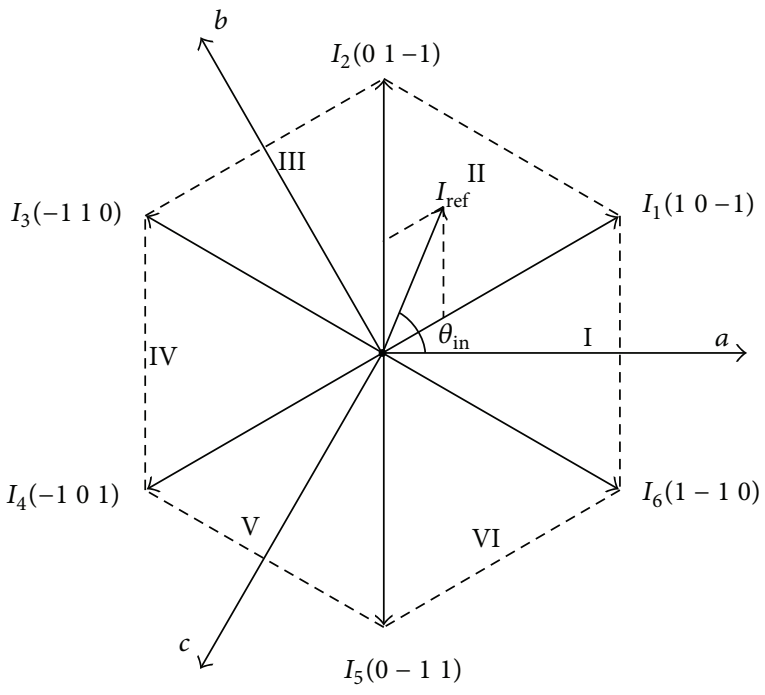

FIgURE 4: Current space vectors of the rectifier.

The principle of space vector modulation (SVM) is shown in Figure 4. $I_{\text {ref }}$ is the reference current space vector. $\theta_{\text {in }}$ is the angle of $I_{\text {ref. }}$.

According to the principle of space vector PWM,

$$
\begin{aligned}
& t_{1}=\frac{m_{\mathrm{rec}} T_{s} \sin \left(\pi / 2-\theta_{\mathrm{in}}\right)}{\sin (\pi / 3)}, \\
& t_{2}=\frac{m_{\mathrm{rec}} T_{s} \sin \left(\theta_{\mathrm{in}}-\pi / 6\right)}{\sin (\pi / 3)}, \\
& t_{0}=T_{s}-t_{1}-t_{2},
\end{aligned}
$$

$$
\begin{aligned}
& d_{1}=\frac{t_{1}}{T_{s}}, \\
& d_{2}=\frac{t_{2}}{T_{s}}, \\
& d_{0}=\frac{t_{0}}{T_{s}} .
\end{aligned}
$$

In (4), $m_{\text {rec }}$ is modulation index for the rectifier, which can be defined as

$$
m_{\mathrm{rec}}=\frac{I_{\mathrm{ref}}}{I_{\mathrm{dc}}}
$$

In order to ensure the sinusoidal input current, the modulation index $m_{\text {rec }}$ cannot be larger than 1 ,

$$
m_{\text {rec }} \leqslant 1
$$

In order to maintain the input power factor as unity, phase angle of $I_{\text {ref }}, \theta_{\text {in }}$ should follow the phase angle of input space vector voltage $U_{\text {in }}$, so the voltage of dc-link is as follows:

$$
\begin{aligned}
& U_{\mathrm{dc}}=m_{\mathrm{rec}} \cdot U_{\mathrm{in}}, \\
& U_{\mathrm{in}}=u_{a}+u_{b} \cdot \mathrm{e}^{j 2 \pi / 3}+u_{c} \cdot \mathrm{e}^{-j 2 \pi / 3} .
\end{aligned}
$$

In (9), $u_{a}, u_{b}$, and $u_{c}$ are the three phase voltages of input sides. In order to obtain the maximum voltage ratio of the rectifier, $m_{\text {rec }}$ should be 1 .

The inverter is controlled as voltage source converter, and the rectifier can be seen as a voltage source in dc-link. The conventional SVPWM algorithm can be used in the inverter, shown in Figure 5:

$$
\begin{aligned}
& T_{1}=\frac{m_{\mathrm{inv}} T_{s} \sin (\pi / 3-\theta)}{\sin (\pi / 3)}, \\
& T_{2}=\frac{m_{\mathrm{inv}} T_{s} \sin (\theta)}{\sin (\pi / 3)},
\end{aligned}
$$




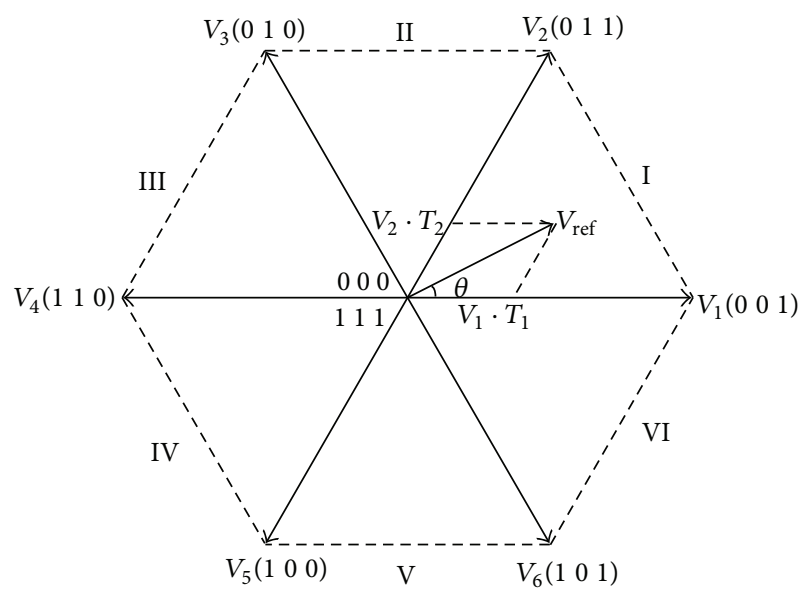

FIGURE 5: SVPWM for inverter when $0<\theta \leq \pi / 3$.

$$
\begin{aligned}
T_{0} & =T_{s}-T_{1}-T_{2}, \\
D_{1} & =\frac{T_{1}}{T_{s}}, \\
D_{2} & =\frac{T_{2}}{T_{s}}, \\
D_{0} & =\frac{T_{0}}{T_{s}}, \\
m_{\mathrm{inv}} & =\frac{U_{\mathrm{ref}}}{U_{\mathrm{dc}}} .
\end{aligned}
$$

In (10), $T_{s}$ is the period of a switching cycle. $m_{\text {inv }}$ is the modulation index of inverter. $D_{0}, D_{1}$, and $D_{2}$ are the duty cycles of the zero vectors, vectors $V_{1}$ and $V_{2}$, respectively. $U_{\text {ref }}$ is the reference space voltage vector and $U_{\mathrm{dc}}$ is the voltage of dc-link.

From (8) and (9), when the input voltages are symmetrical, the voltage of dc-link is constant. The modulation index of inverter is determined by the reference output space voltage vector. The calculation of duty cycles $D_{0}, D_{1}$, and $D_{2}$ will be simple.

2.2. Commutation and PWM Sequence. Generally, a bidirectional switch in matrix converters is constructed by two IGBTs and two diodes or two RB-IGBTs. Commutations between two bidirectional switches need four steps with voltage/current signal. Figure 6 is the process of four-step commutation with voltage signal. $t_{c 0}, t_{c 1}, t_{c 2}$, and $t_{c 3}$ are the times for four-step commutation.

In IMC, the inverter is a conventional voltage source converter and its commutation is traditional. When the inverter is on zero-vector state, the current of dc-link is zero. The commutation of the bidirectional switches in the rectifier can be achieved during this period, and zero-current switching commutation can be realized. The PWM sequence of IMC is shown in Figure 7 and ZCS commutation is shown in Figure 8. $t_{c 0}$ and $t_{c 1}$ are the switching times for two-step commutation.

Compared with the conventional PWM algorithm [1922], the proposed PWM algorithm increases one switching action in rectifier, which is a ZCS process. ZCS commutation is much simpler than four-step commutation and it needs no voltage or current signals. So voltage or current sensor in dclink can be omitted.

2.3. Realization of SVM Algorithm and Commutation Method. In order to realize the SVM algorithm and commutation strategy, a control platform based on DSP and CPLD is implemented, shown in Figure 9. DSP TMS320F2812 of TI is to realize SVM algorithm and CPLD EPM9320LC84-15 of Altera is to realize the commutation strategy for bidirectional switches in rectifier.

The input sectors Sci1 Sci6 and output sectors Svo1 Svi6 are determined with the angle of input voltage and output voltage with DSP. And 8 PWM signals, which are shown in Figure 10, are generated by SVM and SVPWM algorithms with DSP. The 8 PWM signals are not the drive signals for the IGBTs. A decoder for drive signals is needed. CPLD is used to decode drive signals from PWM sequences and realize two-step ZCS commutation. With the PWM signals PWM18 , input sectors, and output sectors, the drive signals for the bidirectional switches can be shown as expression (11), where $S_{i+}$ is the upper bridge and $S_{i-}$ is the lower bridge, $i=a, b, c$.

According to the SVM algorithm for rectifier, the commutation of bidirectional switches occurs between the upper bridges $\left(S_{a+}, S_{b+}, S_{c+}\right)$ and lower bridges $\left(S_{a-}, S_{b_{-}}, S_{c_{-}}\right)$. From Figure 4 , the input current vector $I_{1}(1,0,-1)$ will change to $I_{2}(0,1,-1)$, and the commutation is $S_{a+}$ to $S_{b+}$. The commutation process can be described by the state of RBIGBTs in the rectifier $\left[S_{a+} S_{a_{-}} S_{b_{+}} S_{b_{-}} S_{c+} S_{c^{-}}\right]$. The process of commutation is $\left[\begin{array}{llllll}1 & 0 & 0 & 0 & 0 & 1\end{array}\right]-\left[\begin{array}{llllll}0 & 0 & 0 & 0 & 0 & 1\end{array}\right]$ $\left[\begin{array}{llllll}0 & 0 & 1 & 0 & 0 & 1\end{array}\right]$. Because the commutation is zero-current switching, the commutation of rectifier is the same as inverter. Only the dead time is needed:

$$
\begin{aligned}
& S_{a+}=\mathrm{Sci} 1+\mathrm{Sci} 6 \cdot(1 \oplus \mathrm{PWM} 2)+\mathrm{Sci} 2 \cdot \mathrm{PWM} 1 \\
& +\mathrm{Sci} 4 \cdot(\mathrm{PWM} 1 \oplus \mathrm{PWM} 2) \text {, } \\
& S_{a_{-}}=\mathrm{Sci} 4+\mathrm{Sci} 3 \cdot(1 \oplus \mathrm{PWM} 2)+\mathrm{Sci} 5 \cdot \mathrm{PWM} 1+\mathrm{Sci} 1 \\
& \text { · }(\mathrm{PWM} 1 \oplus \mathrm{PWM} 2) \text {, } \\
& S_{b+}=\mathrm{Sci} 3+\mathrm{Sci} 2 \cdot(1 \oplus \mathrm{PWM} 2)+\mathrm{Sci} 4 \cdot \mathrm{PWM} 1 \\
& + \text { Sci6 } \cdot(\text { PWM1 } \oplus \text { PWM2), } \\
& S_{b_{-}}=\text {Sci6 }+ \text { Sci5 } \cdot(1 \oplus \text { PWM2 })+\text { Scil } \cdot \text { PWM1 + Sci3 } \\
& \cdot(\mathrm{PWM} 1 \oplus \mathrm{PWM} 2) \text {, } \\
& S_{c+}=\mathrm{Sci} 5+\mathrm{Sci} 4 \cdot(1 \oplus \mathrm{PWM} 2)+\mathrm{Sci} 6 \cdot \mathrm{PWM} 1 \\
& +\mathrm{Sci} 2 \cdot(\mathrm{PWM} 1 \oplus \mathrm{PWM} 2), \\
& S_{c-}=\mathrm{Sci} 2+\mathrm{Scil} \cdot(1 \oplus \mathrm{PWM} 2)+\mathrm{Sci} 3 \cdot \mathrm{PWM} 1+\mathrm{Sci} 5 \\
& \text { · }(\mathrm{PWM} 1 \oplus \mathrm{PWM} 2) \text {. }
\end{aligned}
$$



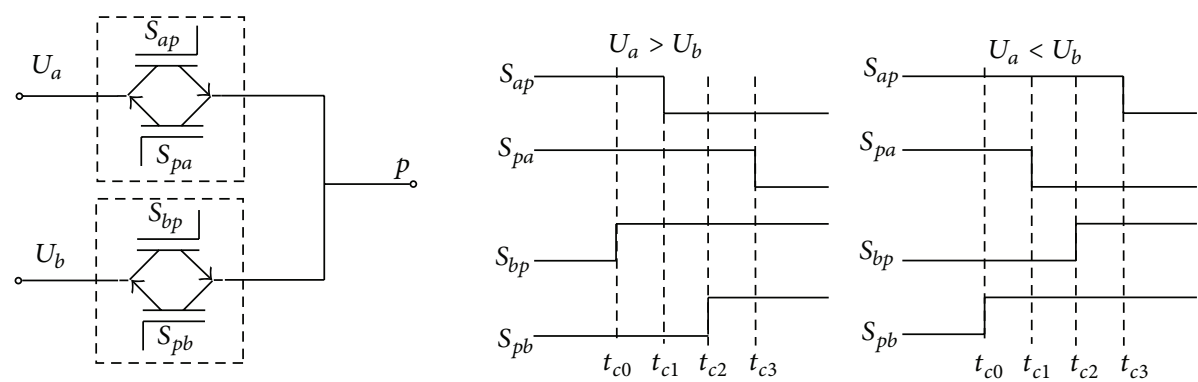

FIGURE 6: Four-step commutation for bidirectional switches of RB-IGBT with voltage signal.

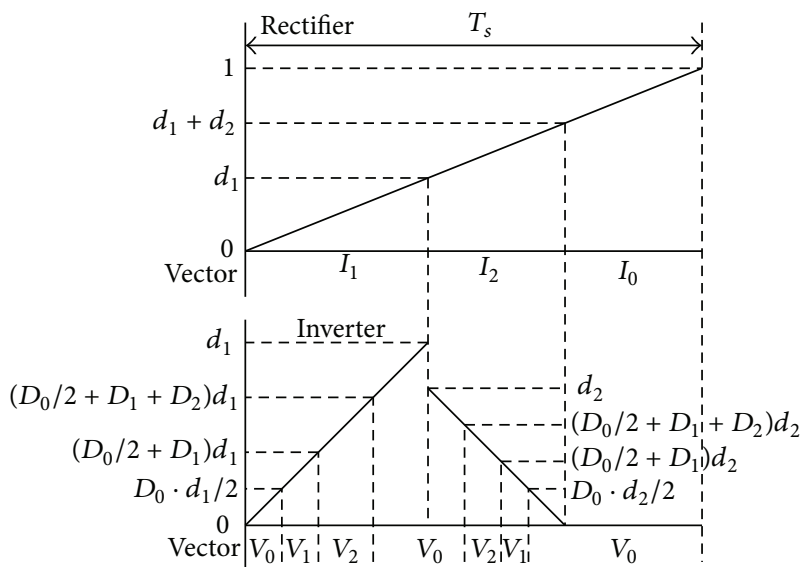

FIGURE 7: PWM sequence for IMC.
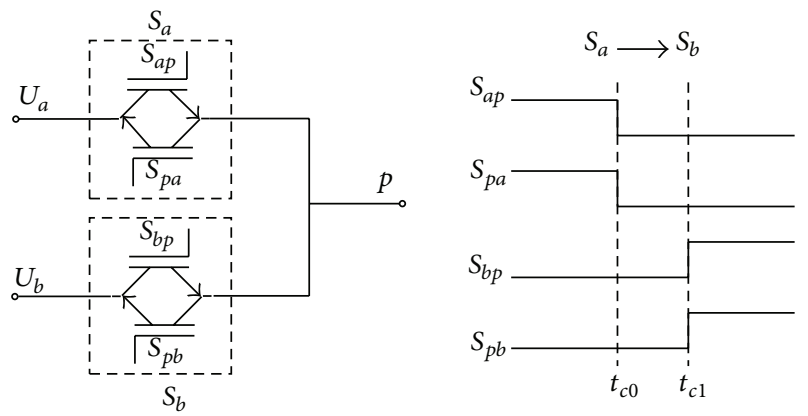

FIGURE 8: Two-step commutation for bidirectional switches of ZCS.

\section{Power Factor Control of IMC}

According to the SVM algorithm, power factor of IMC can be controlled by changing the angle of the reference input current vector, shown in Figure 11. The phase difference of current vector and voltage vector is $\varphi$ and power factor is $\cos \varphi$.

It is assumed that, on the input side,

$$
\begin{aligned}
& u_{a}=U_{m} \cos \left(\omega_{i} t\right), \\
& u_{b}=U_{m} \cos \left(\omega_{i} t-\frac{2 \pi}{3}\right), \\
& u_{c}=U_{m} \cos \left(\omega_{i} t+\frac{2 \pi}{3}\right) .
\end{aligned}
$$

TABLE 2: Sectors of input current space vector.

\begin{tabular}{lc}
\hline Input sector & Phase angle $\omega_{i} t$ \\
\hline 1 & {$[-\pi / 6, \pi / 6)$} \\
2 & {$[\pi / 6, \pi / 2)$} \\
3 & {$[\pi / 2,5 \pi / 6)$} \\
4 & {$[5 \pi / 6,7 \pi / 6)$} \\
5 & {$[7 \pi / 6,3 \pi / 2)$} \\
6 & {$[3 \pi / 2,11 \pi / 6)$} \\
\hline
\end{tabular}

And the reference input currents are

$$
\begin{aligned}
& i_{a}=I_{m} \cos \left(\omega_{i} t-\varphi\right), \\
& i_{b}=I_{m} \cos \left(\omega_{i} t-\frac{2 \pi}{3}-\varphi\right), \\
& i_{c}=I_{m} \cos \left(\omega_{i} t+\frac{2 \pi}{3}-\varphi\right) .
\end{aligned}
$$

The active power on input side is

$$
P=u_{a} i_{a}+u_{b} i_{b}+u_{c} i_{c}=\frac{3}{2} U_{m} I_{m} \cos \varphi .
$$

From (14), $\varphi$ is power angle. When $\varphi>0$, IMC absorbs reactive power. When $\varphi<0$, IMC generates reactive power.

From Figure 1, the inverter of IMC is voltage source converter. The voltage of dc-link $u_{\mathrm{pn}}$ should be positive. Otherwise, the reverse recovery diode for IGBT will be shortcircuited and the semiconductor may be damaged.

The sectors of input current space vector can be divided by the angle of input voltage space vector, which is shown in Table 2.

According to Table 2, the corresponding relationship of input sector and input voltage interval is shown in Figure 12. Input sector I-VI is corresponding with voltage interval 1-6. In order to maintain the DC-link voltage being positive, the relationship of line voltage and phase angle in each sector is shown in Table 3.

In order to maintain the dc-link voltage being positive, the regulation range of $\varphi$ is $[-\pi / 6, \pi / 6]$. In the applications of power factor control, the parameter of input $L C$ filters has effect of power factor control. The simplified circuit of input $L C$ filters is shown in Figure 13.

In Figure 13, $U_{s}$ is input source voltage vector. $I_{s}$ is input source current vector. $U_{\text {in }}$ and $I_{\text {in }}$ are input voltage 


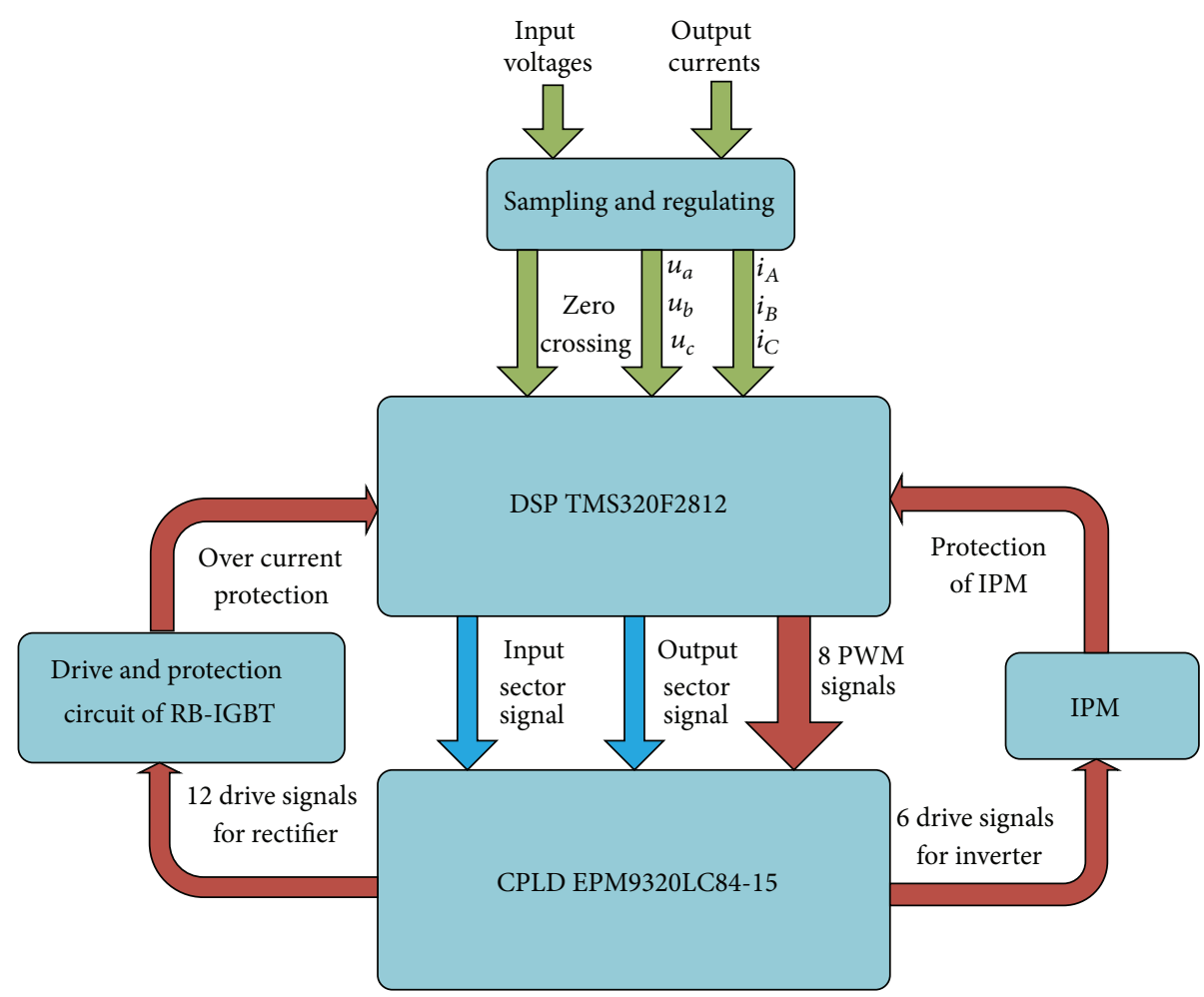

FIGURE 9: Control platform based on DSP and CPLD.

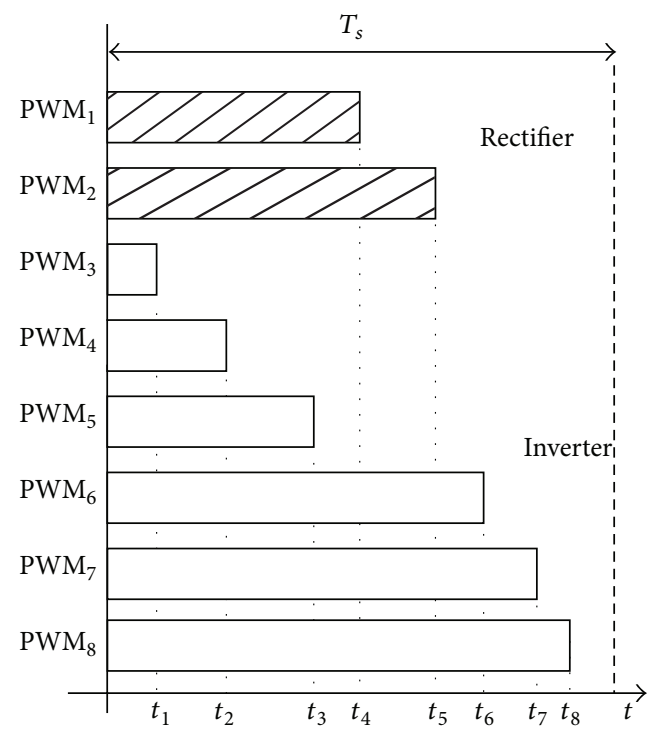

FIGURE 10: PWM segments generated by DSP.

and current vector. Because $U_{\text {in }}$ will be influenced by SVM algorithm, $U_{s}$ is used as the reference input voltage vector. $I_{\text {in }}$ is the reference input current vector. The parameters of input $L C$ filters are $L_{a}=L_{b}=L_{c}=L=0.7 \mathrm{mH}, C_{a}=C_{b}=$ $C_{c}=C=20 \mu \mathrm{F}$. Assume that input source voltage vector is $U_{s}=U_{m} \angle \alpha$ and input current vector is $I_{\text {in }}=I_{m} \angle(\alpha-\varphi)$. $I_{m}$ is decided by the load current and can be calculated with the modulation index of IMC and the amplitude of output currents.

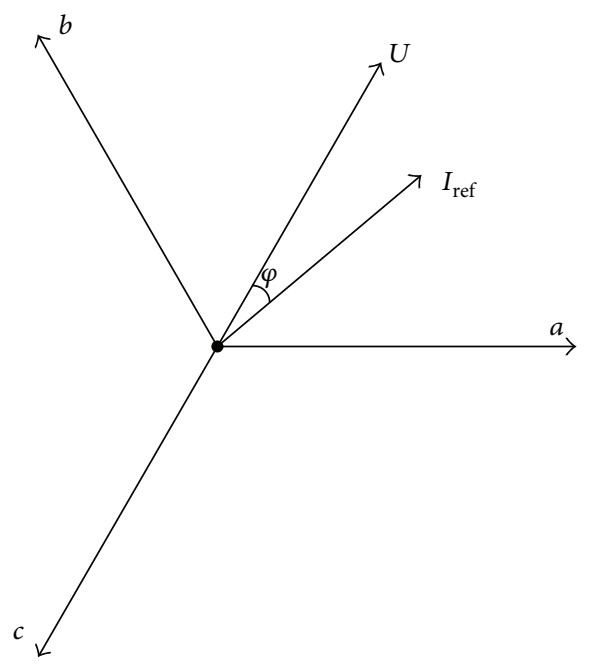

FIGURE 11: The principle of power factor control.

From Figure 13, the differential equations for $L C$ filters can be built as follows:

$$
\begin{gathered}
U_{s}-U_{\text {in }}=L \frac{d I_{s}}{d t}, \\
I_{s}-I_{\text {in }}=C \frac{d U_{\text {in }}}{d t} .
\end{gathered}
$$

Then, the input source current $I_{s}$ is as follows:

$$
L C \frac{d^{2} I_{s}}{d t^{2}}+I_{s}-\left(I_{\mathrm{in}}+C \frac{d U_{s}}{d t}\right)=0
$$




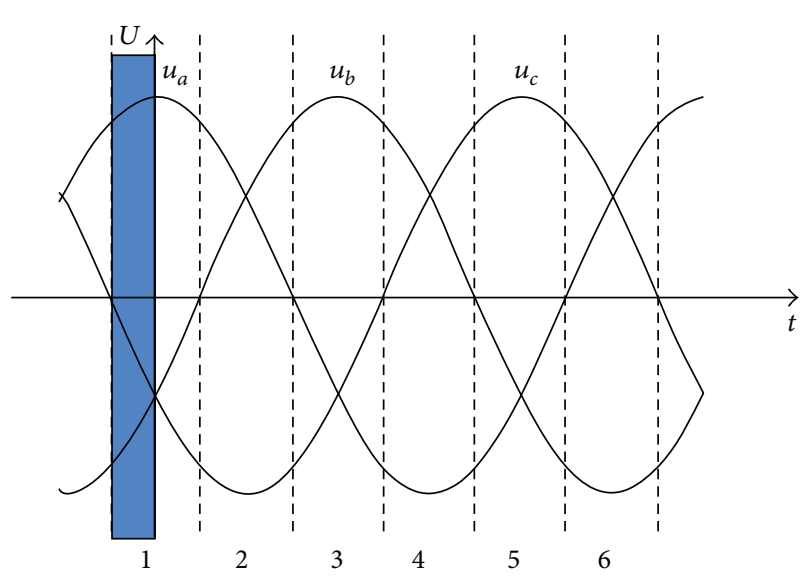

(a) Input voltage intervals

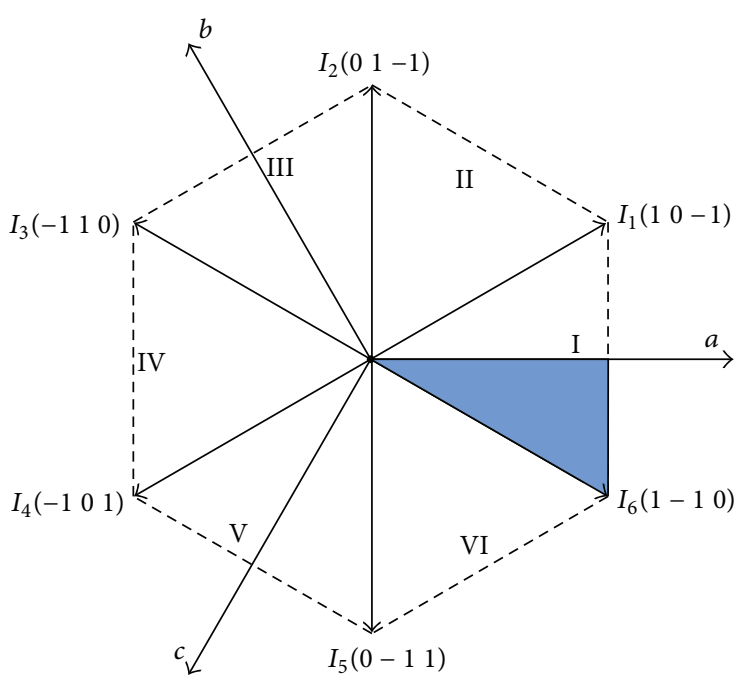

(b) Sector of input current space vector

FIGURE 12: Input voltage interval and sector of input current space vector.

TABLE 3: Relationship of line voltage and phase angle.

\begin{tabular}{llcc}
\hline Sector & \multicolumn{2}{c}{ Line-line voltage } & Phase angle $\omega_{i} t$ \\
\hline 1 & $u_{a b} \geq 0$ & $u_{a c} \geq 0$ & {$[-\pi / 3, \pi / 3)$} \\
2 & $u_{a c} \geq 0$ & $u_{b c} \geq 0$ & {$[0,2 \pi / 3)$} \\
3 & $u_{b c} \geq 0$ & $u_{b a} \geq 0$ & {$[\pi / 3, \pi)$} \\
4 & $u_{b a} \geq 0$ & $u_{c a} \geq 0$ & {$[2 \pi / 3,4 \pi / 3)$} \\
5 & $u_{c a} \geq 0$ & $u_{c b} \geq 0$ & {$[\pi, 5 \pi / 3)$} \\
6 & $u_{c b} \geq 0$ & $u_{a b} \geq 0$ & {$[4 \pi / 3,2 \pi)$} \\
\hline
\end{tabular}

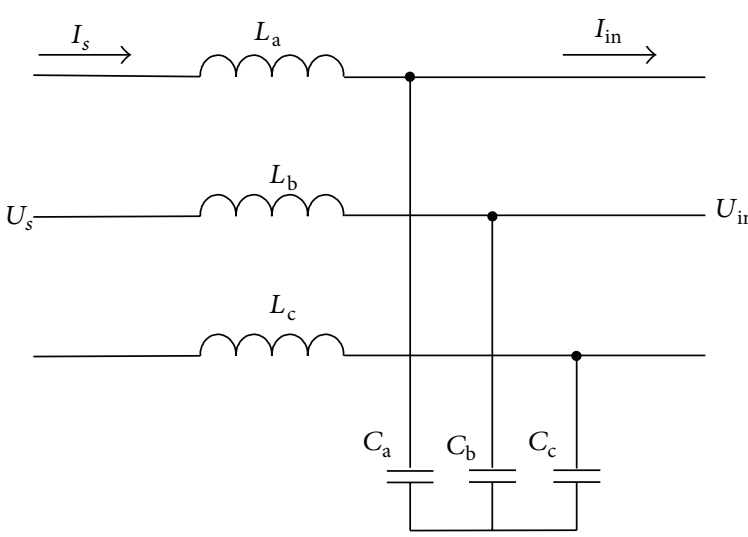

FIGURE 13: Simplified circuit of input $L C$ filters.

Considering the fundamental part of input current and ignoring harmonics current and dynamic process, input source current is expressed as $I_{s}=I_{x} \angle \beta$. From (16),

$$
\begin{aligned}
I_{x}\left(1-L C \omega_{i}^{2}\right) \angle \beta= & I_{m} \angle(\alpha-\varphi) \\
& -C \omega_{i} U_{m} \angle\left(\alpha-\frac{1}{2} \pi\right) .
\end{aligned}
$$

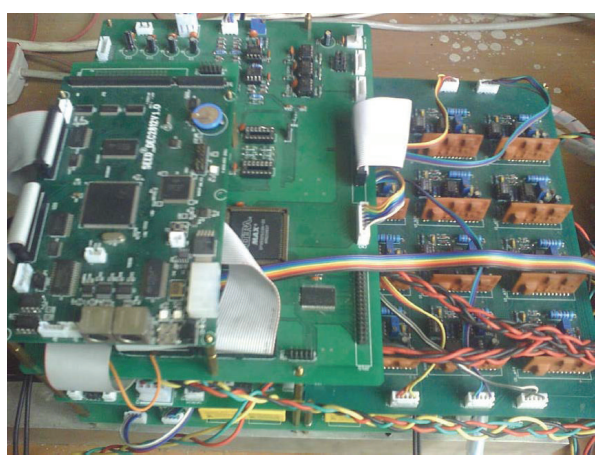

FIGURE 14: Prototype of RB-IGBT based indirect matrix converter.

The amplitude and angle of input source current can be got as follows:

$$
\begin{aligned}
& I_{x}=\frac{\sqrt{\left(I_{m}\right)^{2}+\left(C \omega_{i} U_{m}\right)^{2}-2 C \omega_{i} U_{m} I_{m} \sin \varphi}}{1-L C \omega_{i}^{2}}, \\
& \beta=\alpha+\arctan \left(\frac{C \omega_{i} U_{m}-I_{m} \sin \varphi}{I_{m} \cos \varphi}\right) .
\end{aligned}
$$

From (18), power angle is related to the capacitor of $L C$ filters, the amplitude of load current, and the angle of reference input current vector.

\section{Experimental Results}

The prototype of RB-IGBT based indirect matrix converter has been developed, shown in Figure 14. It mainly includes power circuit, RB-IGBT gate drive circuit, signal processing circuit, CPLD and DSP based control board, and heat sink. The rectifier is composed of the RB-IGBT module 18MBI100W-060A from Fuji Electric [31]. 


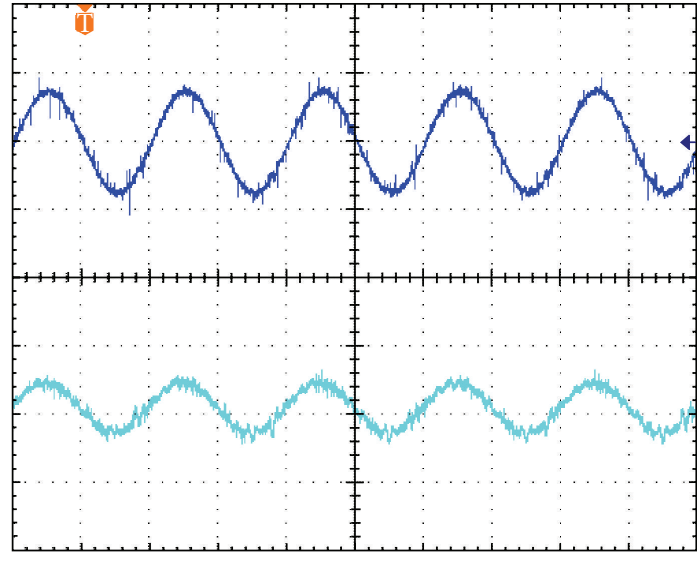

(a) Input phase voltage (25 V/div) and current (5 A/div)

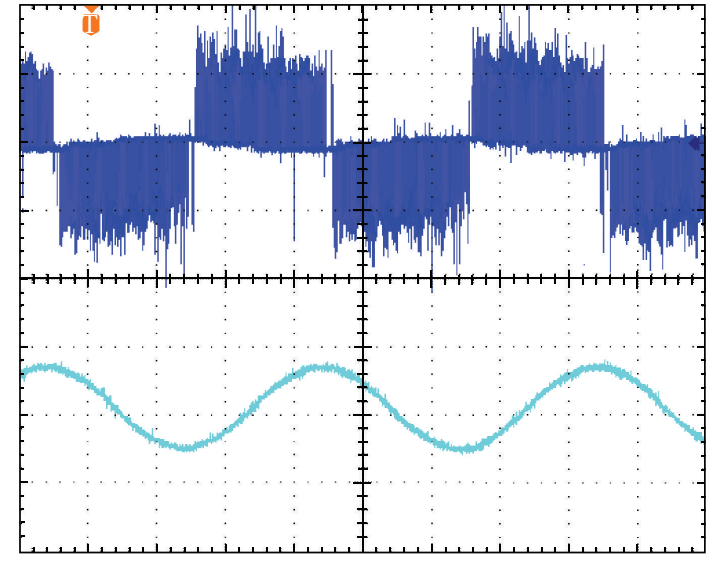

(b) Output line-to-line (25 V/div) and current (5 A/div)

FIGURE 15: Experimental waveforms of proposed PWM algorithm.

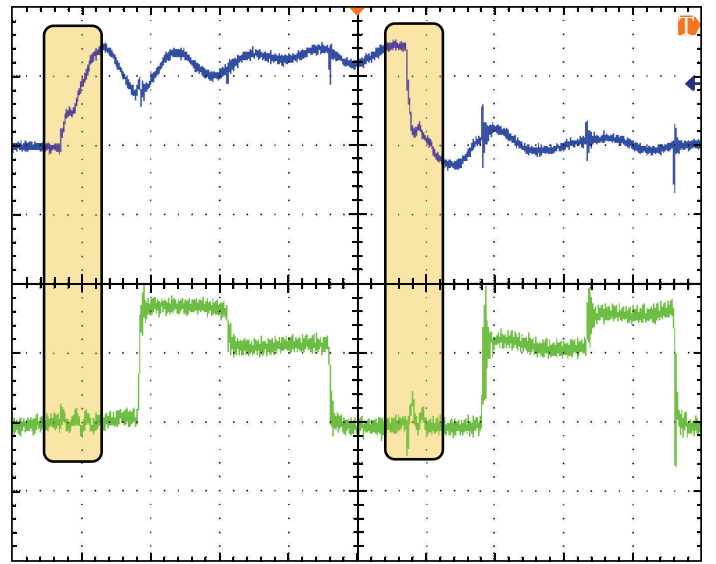

FIGURE 16: The voltage (25 V/div) across RB-IGBT and the dc-link current $(5 \mathrm{~A} / \mathrm{div})$ during zero-current switching.

In order to verify the proposed PWM algorithm and sequence, experimental tests on IMC prototype have been carried out. The parameters of the input filters are $L=$ $0.7 \mathrm{mH}, C=20 \mu \mathrm{F}$, and $R=200 \Omega$. The sampling frequency is $10 \mathrm{kHz}$. Input voltage is $50 \mathrm{~Hz}$ and output frequency is $25 \mathrm{~Hz}$. The load is an induction motor.

Figure 15 gives the experimental waveforms of SVM algorithm. The THD of output current is $1.06 \%$. The THD of input current is $6.39 \%$. Figure 16 shows the voltage of the bidirectional switch $S_{\text {ap }}-U_{\text {sap }}$ and dc-link current $i_{\mathrm{dc}}$ when the commutation of bidirectional switches occurs. It can be seen that dc-link current is around zero at the commutation point, which means that zero-current switching is realized.

The waveforms of input voltage and current when the power factor angle is setting as $-2 \pi / 15$, zero, and $2 \pi / 15$ are shown in Figures 17-19, respectively.

The power factor angle of experiment can be shown in Table 4. The theoretical value of power factor angle can be calculated by expression (18).

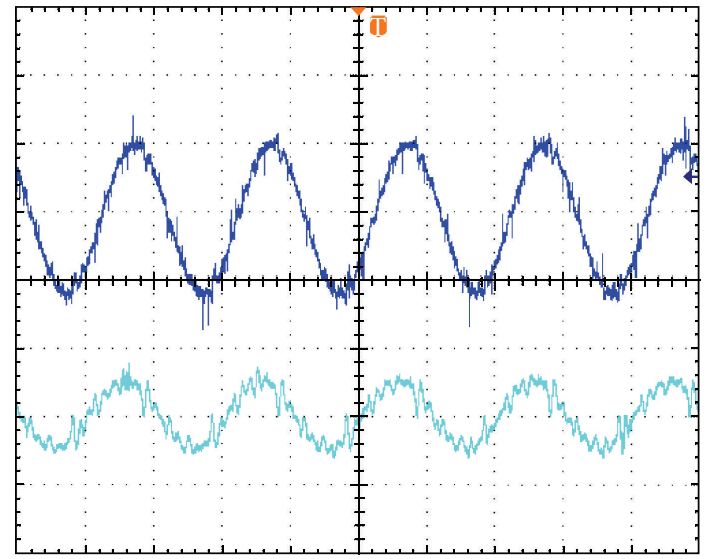

FIGURE 17: The experiment waveforms of input $(25 \mathrm{~V} /$ div $)$ and current ( $5 \mathrm{~A} / \mathrm{div})$ when power factor angle is $-2 \pi / 15$.

TABLE 4: Comparison of theoretical value and experimental result of power factor angle.

\begin{tabular}{lcc}
\hline $\begin{array}{l}\text { Setting power } \\
\text { factor angle }\end{array}$ & Calculated by (18) & Experimental result \\
\hline$\varphi=-24^{\circ}$ & $-26.3^{\circ}$ & $-28.8^{\circ}$ \\
$\varphi=0$ & $-7.7^{\circ}$ & $-14.4^{\circ}$ \\
$\varphi=24^{\circ}$ & $14^{\circ}$ & $10.8^{\circ}$ \\
\hline
\end{tabular}

\section{Conclusions}

In this paper, a SVM algorithm for indirect matrix converter with zero-current switching commutation for bidirectional switches is realized based on a control platform of DSP and CPLD. SVM for the rectifier and SVPWM for the inverter stage are described. PWM sequence of the SVM algorithm can achieve two-step ZCS commutation for the rectifier bidirectional switches. The realization of PWM sequence by DSP and decoding process for drive signals of RB-IGBTs by CPLD are explained in detail. 


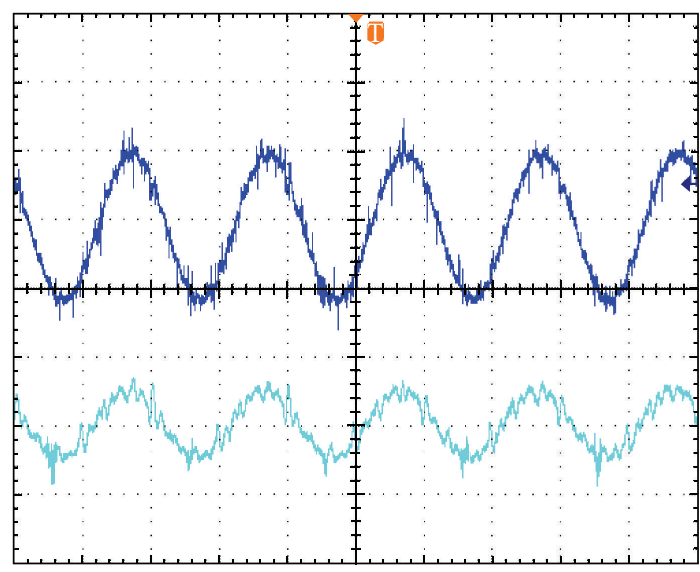

FIgURE 18: The experiment waveforms of input $(25 \mathrm{~V} / \mathrm{div})$ and current $(5 \mathrm{~A} / \mathrm{div})$ when power factor angle is zero.

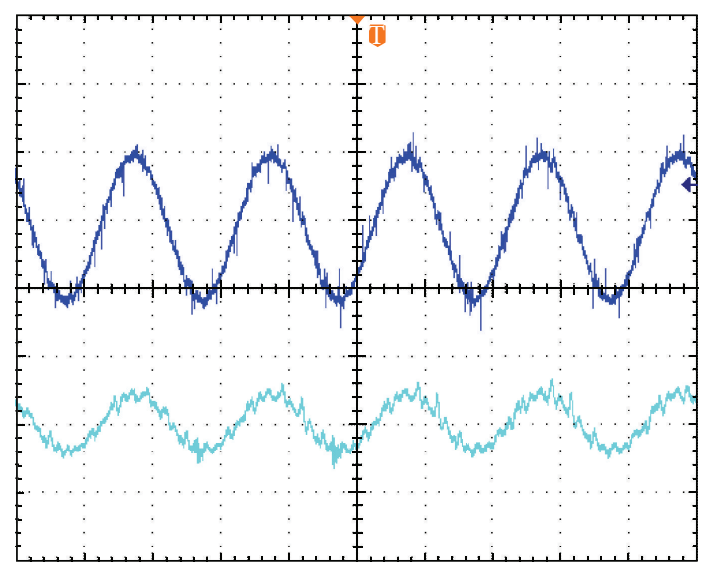

FIgURE 19: The experiment waveforms of input $(25 \mathrm{~V} / \mathrm{div})$ and current ( $5 \mathrm{~A} / \mathrm{div})$ when power factor angle is $2 \pi / 15$.

Based on the modulation strategy, input power factor correction of IMC is discussed. Because the inverter of IMC is VSI, the dc-link voltage should be positive and the regulation range of power angle is $[-\pi / 6, \pi / 6]$. The influence of the parameters in $L C$ filters is analyzed. A prototype of RB-IGBT based indirect matrix converter is implemented. The experimental results show the performance of SVM algorithm and validate the analysis of power factor control of IMC.

\section{Conflict of Interests}

The author declares that there is no conflict of interests regarding the publication of this paper.

\section{References}

[1] P. W. Wheeler, J. Rodríguez, J. C. Clare, L. Empringham, and A. Weinstein, "Matrix converters: a technology review," IEEE Transactions on Industrial Electronics, vol. 49, no. 2, pp. 276288, 2002.
[2] K. Sun, D. N. Zhou, L. P. Huang, and K. Matsuse, "Compensation control of matrix converter fed induction motor drive system under abnormal input voltage conditions," in Proceedings of the IEEE Industry Applications Conference, vol. 1, pp. 623-630, 2004.

[3] L. Wei, T. A. Lipo, and H. Chan, "Matrix converter topologies with reduced number of switches," in Proceedings of the IEEE 33 rd Annual Power Electronics Specialists Conference (PESC '02), vol. 1, pp. 57-63, June 2002.

[4] L. N. Wang, K. Sun, and L. P. Huang, "A novel method to enhance the voltage transfer ratio of matrix converter," in Proceedings of the 30th Annual Conference of IEEE Industrial Electronics Society (IECON '04), vol. 1, pp. 723-728, IEEE, November 2004.

[5] C. Klumpner and F. Blaabjerg, "Two stage direct power converters: an alternative to the matrix converter," in Proceedings of the IEE Seminar on (Digest No. 2003/10100) Matrix Converters, pp. 7/1-7/9, IET, April 2003.

[6] L. Helle, K. B. Larsen, A. H. Jorgensen, S. Munk-Nielsen, and F. Blaabjerg, "Evaluation of modulation schemes for threephase to three-phase matrix converters," IEEE Transactions on Industrial Electronics, vol. 51, no. 1, pp. 158-171, 2004.

[7] A. Alesina and M. Venturini, "Solid-state power conversion: a fourier analysis approach to generalized transformer synthesis," IEEE Transactions on Circuits and Systems, vol. 28, no. 4, pp. 319-330, 1981.

[8] P. Kiatsookkanatorn and S. Sangwongwanich, "A unified PWM method for matrix converters and its carrier-based realization using dipolar modulation technique," IEEE Transactions on Industrial Electronics, vol. 59, no. 1, pp. 80-92, 2012.

[9] M. S. A. Dahidah and V. G. Agelidis, "SHE-PWM technique for single-phase AC-AC matrix converters," in Proceedings of the Australasian Universities Power Engineering Conference (AUPEC '08), pp. 1-8, IEEE, Sydney, Australia, December 2008.

[10] J.-I. Itoh, G. T. Chiang, and K. Maki, "Beatless synchronous PWM control for high-frequency single-pulse operation in a matrix converter," IEEE Transactions on Power Electronics, vol. 28, no. 3, pp. 1338-1347, 2013.

[11] T. Takeshita and H. Fukagawa, "PWM strategy of voltage harmonics minimization for matrix converters," in Proceedings of the Annual Conference on IEEE Industrial Electronics Society, pp. 668-673, November 2010.

[12] S. Kim, Y.-D. Yoon, and S.-K. Sul, "Pulsewidth modulation method of matrix converter for reducing output current ripple," IEEE Transactions on Power Electronics, vol. 25, no. 10, pp. 26202629, 2010.

[13] J. Wang, B. Wu, D. Xu, and N. R. Zargari, "Indirect space-vectorbased modulation techniques for high-power multimodular matrix converters," IEEE Transactions on Industrial Electronics, vol. 60, no. 8, pp. 3060-3071, 2013.

[14] L. X. Wei and T. A. Lipo, "A novel matrix converter topology with simple commutation," in Proceedings of the 36th IEEE IAS Annual Meeting on Industry Applications Conference, vol. 3, pp. 1749-1754, 2001.

[15] C. Klumper, F. Blaabjerg, and P. Thoegersen, "Alternate ASDs: evaluation of the converter topologies suited for integrated motor drives," IEEE Industry Applications Magazine, vol. 12, no. 2, pp. 71-83, 2006.

[16] M. Jussila and H. Tuusa, "Comparison of simple control strategies of space-vector modulated indirect matrix converter under distorted supply voltage," IEEE Transactions on Power Electronics, vol. 22, no. 1, pp. 139-148, 2007. 
[17] C. Klumpner and F. Blaabjerg, "Modulation method for a multiple drive system based on a two-stage direct power conversion topology with reduced input current ripple," IEEE Transactions on Power Electronics, vol. 20, no. 4, pp. 922-929, 2005.

[18] G. Li, K. Sun, L. P. Huang, and S. Igarashi, "RB-IGBT gate drive circuit and its application in two-stage matrix converter," in Proceedings of the 23rd Annual IEEE Applied Power Electronics Conference and Exposition (APEC '08), pp. 245-251, February 2008.

[19] Q. Xiaodong, X. Yanchun, and W. Yuye, "Indirect matrix converter based on investigations of field-oriented control for induction motor," in Proceedings of the 4th IEEE Conference on Industrial Electronics and Applications (ICIEA '09), pp. 709-714, Xi'an, China, May 2009.

[20] T. Friedli, M. L. Heldwein, F. Giezendanner, and J. W. Kolar, "A high efficiency indirect matrix converter utilizing RB-IGBTs," in Proceedings of the IEEE Power Electronics Specialists Conference, pp. 1-7, June 2006.

[21] J. W. Kolar, M. Baumann, F. Schafmeister, and H. Ertl, "Novel three-phase AC-DC-AC sparse matrix converter," in Proceedings of the 17th Annual IEEE Applied Power Electronics Conference and Expositions, pp. 777-791, March 2002.

[22] F. Schafmeister and J. W. Kolar, "Novel modulation schemes for conventional and sparse matrix converters facilitating reactive power transfer independent of active power flow," in Proceedings of the IEEE 35th Annual Power Electronics Specialists Conference, vol. 4, pp. 2917-2923, June 2004.

[23] C. Qi, X. Chen, and Y. Qiu, "Carrier-based randomized pulse position modulation of an indirect matrix converter for attenuating the harmonic peaks," IEEE Transactions on Power Electronics, vol. 28, no. 7, pp. 3539-3548, 2013.

[24] T. D. Nguyen and H.-H. Lee, "Dual three-phase indirect matrix converter with carrier-based PWM method," IEEE Transactions on Power Electronics, vol. 29, no. 2, pp. 569-581, 2014.

[25] G. T. Chiang and J.-I. Itoh, "Comparison of two overmodulation strategies in an indirect matrix converter," IEEE Transactions on Industrial Electronics, vol. 60, no. 1, pp. 43-53, 2013.

[26] T. D. Nguyen and H.-H. Lee, "Modulation strategies to reduce common-mode voltage for indirect matrix converters," IEEE Transactions on Industrial Electronics, vol. 59, no. 1, pp. 129-140, 2012.

[27] R. Peña, R. Cárdenas, E. Reyes, J. Clare, and P. Wheeler, “Control of a doubly fed induction generator via an indirect matrix converter with changing dc voltage," IEEE Transactions on Industrial Electronics, vol. 58, no. 10, pp. 4664-4674, 2011.

[28] M. Ortega, F. Jurado, and J. Carpio, "Control of indirect matrix converter with bidirectional output stage for micro-turbine," IET Power Electronics, vol. 5, no. 6, pp. 659-668, 2012.

[29] J. Wang, B. Wu, D. Xu, and N. R. Zargari, "Phase-shiftingtransformer-fed multimodular matrix converter operated by a new modulation strategy," IEEE Transactions on Industrial Electronics, vol. 60, no. 10, pp. 4329-4338, 2013.

[30] P. C. Loh, F. Blaabjerg, F. Gao, A. Baby, and D. A. C. Tan, "Pulsewidth modulation of neutral-point-clamped Indirect matrix converter," IEEE Transactions on Industry Applications, vol. 44, no. 6, pp. 1805-1814, 2008.

[31] Fuji Electric Corporation, Fuji Electric Power Semiconductor Application Manual, Fuji Electric Corporation, Tokyo, Japan, 2004. 

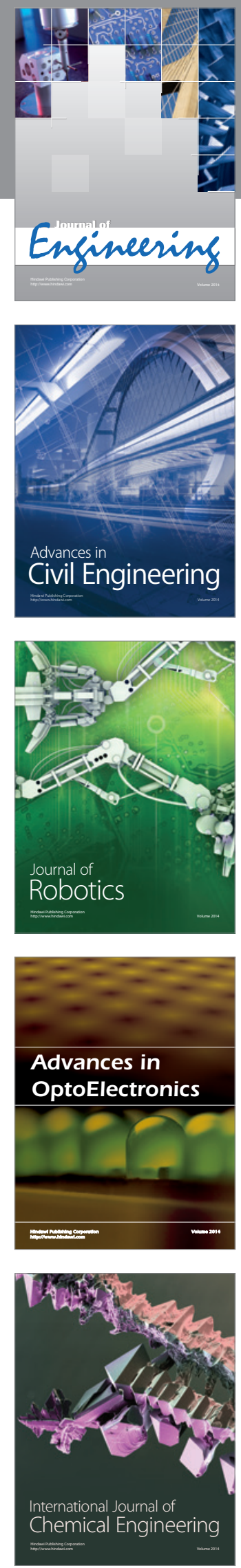

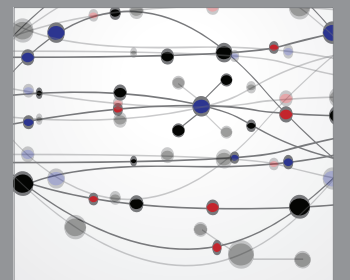

The Scientific World Journal
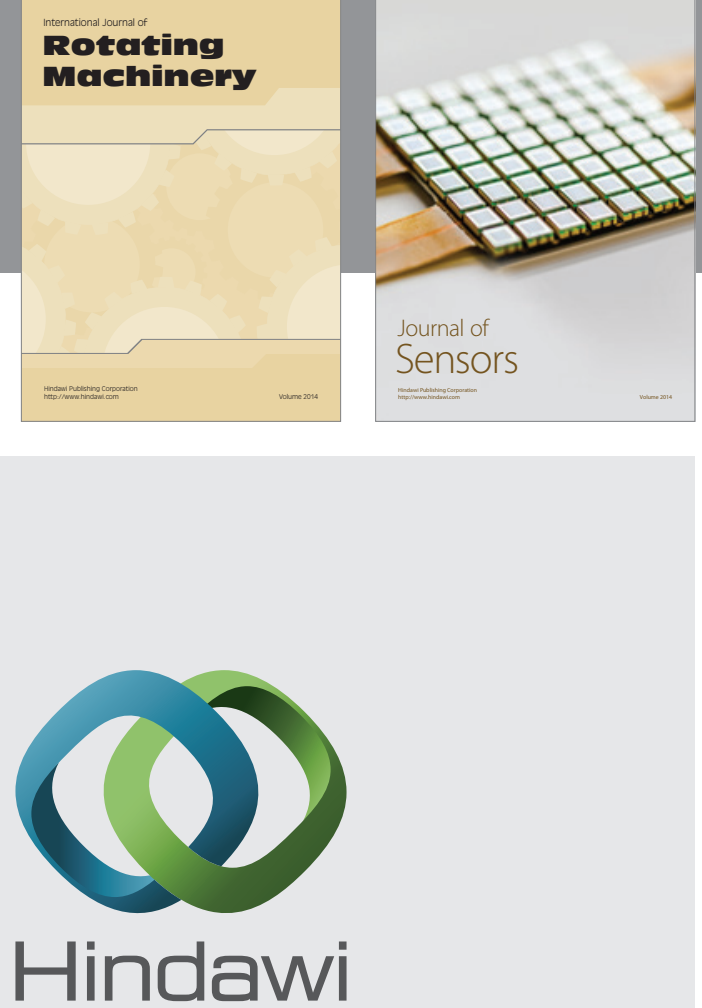

Submit your manuscripts at http://www.hindawi.com
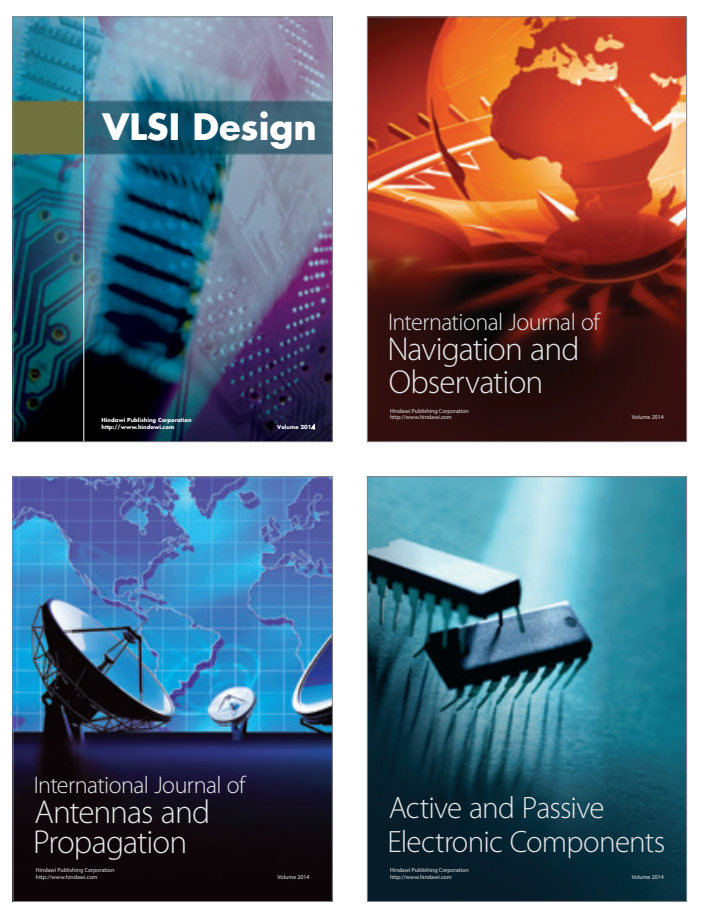
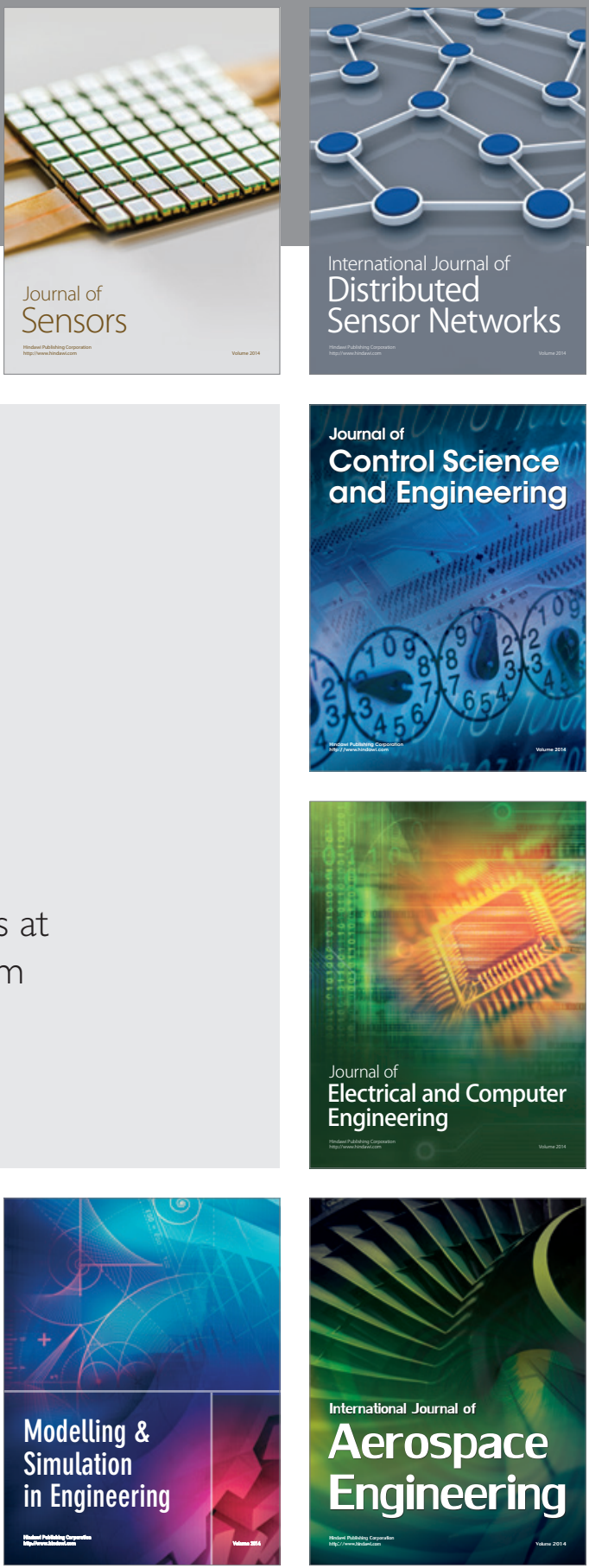

Journal of

Control Science

and Engineering
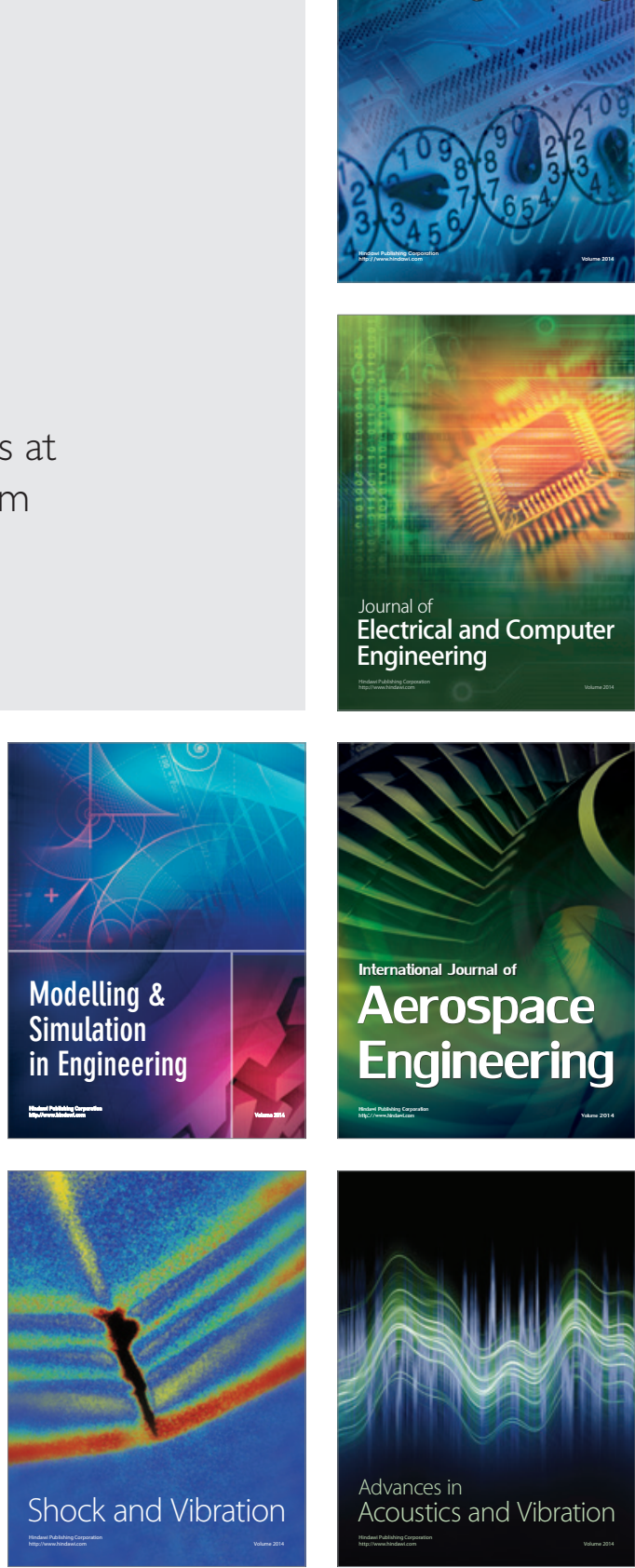